
265 ENKEPHALIN CONCENTRATION WITHIN BRAINSTEM NUCLEI. JL Gingras-Leatherman, MC MCNamara, EE Lawson, Dept. number of physiologic functions. Recently, we reported that ME levels are higher in respiratory-related nuclei in young vs old levels are higher in respiratory-related nuclei in young vs old animals (Brain Res, in press) and speculated these maturational
changes influence the development of cardiopulmonary control. To investigate age related differences in sensitivity to hypoxia, we measured ME concentration [ME] within brainstem nuclei involved in integration of cardiopulmonary control under the following conditions: Grp I: control, breathed RA $\times 6$ hrs; Grp II: $10 \min 10 \% 0_{2}, 20 \min$ RA $\times 6 \mathrm{hrs}$; Grp III: $2 \mathrm{hrs} 10 \% 0_{2}, 4 \mathrm{hrs}$ RA; Grp IV: 4 hrs RA, 2 hrs $10 \% 0$. There were no significant changes in [ME] in any nuclei studied under any condition in the 3 d o animals. Data from the $21 \mathrm{~d} 0$ animals are presented:

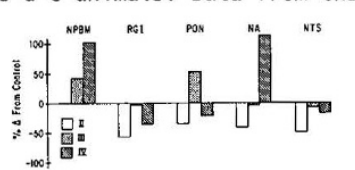
These data suggest 1 ) intermittent These data suggest 1) intermittent
hypoxia (Grp II) decreases [ME] in 21 but not 2 d o anima is 2) recovery (Grp III) occurs in the $21 \mathrm{do}$ animals. Our previous studies showed age-specific changes in under similar conditions (SPR, 1984). These results, taken together, support the concept that neonatal homeostasis is gether, support the concept that neonatal homeostasis is governed by a critical balance of excitatory and inhibitory

\section{$\dagger 266$}

GLUCONEOGENESIS BY THE FETAL SHEEP RIDNEY. Christine A. Gleason, Harriet S. Iwamoto, Institute, Univ. of California and Mt. Zion Hospital, San Francisco, California.

We have consistent1y noted glucose release by the kfdney of the unstressed fetal sheep, but it is not known whether this glucose is produced by gluconeogenesis or by glycogenolysis. To examine this question, we infused ${ }^{14} \mathrm{C}$-1actate intravenous1y into 5 healthy fetal sheep (mean gestational age 130 days) aorta (FA), renal vein (RV), and inferior vena cava. We measured $14 \mathrm{C}-$ glucose and glucose concentrations in the RV and FA, total $1{ }^{14} \mathrm{C}$-radioactivity and lactate concentration in the FA, and renal blood flow by the radioactive microsphere method. We calculated glucose flux across the kidney by the Fick method. Lactate specific activity was not measured; since total we could not calculate the actual quantity of glucose produce from lactate. We could, however, measure the minimum amount of glucose produced from lactate. We found net glucose release by the kidney (mean $3.0 \mathrm{mg} / \mathrm{min} / 100 \mathrm{~g}$ kidney); at least $23 \%$ of this glucose was produced from lactate $(0.7 \mathrm{mg} / \mathrm{min} / 100 \mathrm{~g}$ kidney $)$.

The unstressed fetal sheep kidney is therefore able to produce glucose by gluconeogenesis. This new glucose may be used by the kidney or may contrib
supply. (Supported by $\mathrm{HD} 17618$.)
265 AGE-SPECIFIC SENSITIVITY TO HYPOXIA ON METHIONINEPeds, Duke U, Durham, NC and of is implicated in the modulation of posing young animals to increased cardiopulmonary instability. which had catheters chronically placed in the fetal descending used by the kidney or may contribute to total fetal glucose

$\dagger 268$

LACTATE UPTAKE BY THE FETAL AND NEONATAL SHEEP 208 Bristow, Joseph Itskovitz, and Abraham M. Rudolph, Cardiovascular Research Institute, Univ. of California and Mt. Zion Hospital, San Francisco, California.

In the fetal sheep, lactate is an important metabolic substrate and previous studies have shown placental lactate production and lactate uptake by the fetal liver. In the neonatal sheep, there is no placental lactate source and blood lactate concentrations are lower than in the fetus. To compare the importance of lactate as a substrate for fetal and neonatal liver metabolism, we measured lactate flux across the liver in 16 fetal sheep (mea gestational age 129 days) which had catheters chronically placed In the right or left hepatic vein, portal vein, descending aorta and umbilical vein and in 5 neonatal sheep (mean age 9 days) with similar catheters except for the umbilical vein. In addition, we measured umbilical lactate uptake in the fetal sheep. In the fetus, net hepatic lactate uptake was $5.0 \mathrm{mg} / \mathrm{min} / 100 \mathrm{~g}$. There was a linear correlation between hepatic and umbilical lactate uptake $(\mathrm{r}=0.74, \mathrm{p}<.005)$; hepatic uptake could account for nearly $90 \%$ of umbilical uptake, but hepatic lactate extraction was only $7.7 \%$ of hepatic lactate delivery $(94.2 \mathrm{mg} / \mathrm{min} / 100 \mathrm{~g})$. In the neonate, net hepatic lactate uptake was more than twice the fetal rate $(11.0 \mathrm{mg} / \mathrm{min} / 100 \mathrm{~g})$ and hepatic lactate extraction was $32.9 \%$ of hepatic lactate delivery $(31.0 \mathrm{mg} / \mathrm{min} / 100 \mathrm{~g}$ ). Lactate is therefore an important substrate for both fetal and neonatal 1iver metabolism. Although lactate delivery to the neonatal liver decreases, increased hepatic extraction neonatal liver decreases, Increased hepatic extraction
(Supported by HL24056.)

† HYPEROXIA ALTERS ENDOTHELIAL CELL PROLIFERATION. † 269 Janet E. Graeber, Bert M. Glaser, (Spon. by M.D. Jones, Jr.), Departments of Pediatrics and Ophtha1mology, Johns Hopkins Hospital, Baltimore, MD 21205.

Retinopathy of prematurity (ROP) is characterized by an early vaso-obliterative stage which can be seen experimentally during periods of hyperoxia and a later stage of neovascularization which follows the period of high oxygen exposure. Because endowhich follows the period of high oxygen exposure. Because endozation, we have examined the effects of varying oxygen tensions on endothelial cell proliferation in vitro. Fetal bovine aortic endothelial cells (FBAE) were plated at a density of 40,000 ce11s/35m culture dish and maintained in $20 \% \mathrm{O}_{2} / 75 \% \mathrm{~N}_{2} / 5 \% \mathrm{CO}_{2}$ at $37^{\circ} \mathrm{C}$. After 48 hours, FBAE were exposed to $95 \% \mathrm{O}_{2} / 5 \% \mathrm{CO}_{2}$ (hyperoxia) or $20 \% \mathrm{O}_{2} / 75 \% \mathrm{~N}_{2} / 5 \% \mathrm{CO}_{2}$ (control) at $37^{\circ} \mathrm{C}$ for 48 hours Following oxygen exposure, all cells were placed in $20 \% 0_{2} / 75 \%$ $\mathrm{N}_{2} / 5 \% \mathrm{CO}_{2}$ at $37^{\circ} \mathrm{C}$ and followed for 7 days. $\mathrm{pH}$ and $\mathrm{pCO}_{2}$ of the media were maintained at 7.4 and $30-37$ torr respectively. Cell counts were performed daily (Coulter Counter). In cells exposed to 48 hours of hyperoxia, FBAE growth ceased (100\% inhibition) while control cells continued to proliferate. When oxygen-exposed FBAE were returned to a normoxic environment, they again proliferated, with growth rates now approximating that of control cells. During limited periods of hyperoxia, FBAE growth is arrested. In a normoxic environment, $\mathrm{O}_{2}$-exposed $\mathrm{FBAE}$ again proliferate. Direct effects of hyperoxia on vascular endothelial cell proliferation may play a role in the vascular changes of cel1
ROP.

OXYGENATION DOES NOT STIMULATE HEPATIC GLUCOSE PRO-

267 Abraham M. Rudolph. Cardiovascular Research Institute University of California and Mt. Zion Hospital, San Francisco, CA Previous studies have demonstrated zero glucose flux and absence of gluconeogenesis by the fetal liver. Shortly after birth, however, the newborn liver releases glucose both by glycogenolysis and by gluconeogenesis. Warnes et al have suggested that oxygen availability stimulates hepatic gluconeogenesis at birth. To test whether an increase in blood p02 stimulates hepatic release of glucose, we studied 6 healthy fetal lambs at 136.5 days which had catheters chronically maintained in the right or left hepatic vein (HV), umbilical vein, inferior vena cava, and fetal descending aorta (FA), and a large tube in the trachea. We ventilated the lambs in utero, first with $5 \% \mathrm{CO}_{2}, 3 \% \mathrm{O}_{2}, 92 \% \mathrm{~N}_{2}$ and then with $95 \% \mathrm{O}_{2}, 5 \% \mathrm{CO}_{2}$. We measured hepatic blood flow by the microsphere method and hepatic glucose (G1u) flux

method. Our results (mean $\pm \mathrm{SD}$ ) are as follows:

\begin{tabular}{ccccc} 
& $\begin{array}{c}\text { FA PaO2 } \\
\text { (torr) }\end{array}$ & $\begin{array}{c}\mathrm{HV}[\mathrm{Glu} / \mathrm{mg}) \\
\text { Contro1 }\end{array}$ & $\begin{array}{c}\text { Hepatic Flow Hepatic G1u F1 } \\
\text { (m1/min } / 100 \mathrm{~g})(\mathrm{mg} / \mathrm{min} / 100 \mathrm{~g})\end{array}$ \\
\cline { 2 - 5 } & $19 \pm 3.7$ & $17 \pm 3.5$ & $410 \pm 238$ & $-7.62 \pm 10.6$
\end{tabular}

$\begin{array}{lllll}\text { Control } & 19 \pm 3.7 & 17 \pm 3.5 & 410 \pm 238 & -7.62 \pm 10.6 \\ 95 \% \mathrm{O}_{2} & 80 \pm 59 & 20 \pm 6.5 & 323 \pm 229 & -7.89 \pm 8.8\end{array}$

These near-term lambs did demonstrate hepatic glucose production in the control period. However, although the results suggest that oxygenation increases HV Glu concentration, and decreases liver blood flow, the differences are not significant, and oxygenation did not change hepatic glucose flux. (Supported by HL24056.)
IS EGF A MEDIATOR OF GLUCOCORTICOID ACTION ON

270 DEVELOPING FETAL LUNG? Ian Gross, Di ane W. Dynia, Yale Sch of Med, Dept. Ped., New Haven, CT and Univ. Texas, Southwestern Medical Center, Dept. Ped。, Dallas, Texas.

EGF is believed to enhance fetal lung maturation. We have examined the interactions between EGF and corticosteroids in explants of fetal rat lung in a serum free organ culture system. choline (PC) and disaturated PC (DSPC) in a dose dependent $\mathrm{ng} / \mathrm{mI})$. There was also a 6 fold increase in acetate incorporation into phosphatidylglycerol. $T_{3}$ and EGF together had an additive effect on choline incorporation into DSPC, whereas exposure to saturating doses of EGF plus dexamethasone (dex) had no greater effect than did dex alone, suggesting that the 2 agents act at similar metabolic sites.

We further explored the interaction between EGF and dex。 Dex increased the activity of cholinephosphate cytidylyltransferase, the rate limiting enzyme of PC synthesis, but EGF had no effect on this enzyme. We also examined the influence of dex on EGF binding and separately that of EGF on glucocorticoid binding. EGF had no effect on specific cytoplasmic or nuclear glucocortiin specific EGF binding capacity.

One of the ways in which corticosteroids stimulate lung maturation may be by increasing EGF binding capacity with subsequent amplification of EGF action. EGF stimulated the incorporation of chol ine into phosphatidylfashion with half the maximal effect occurring at $1.03 \mathrm{nM}(6.31$ coid binding, but exposure to dex resulted in a 2 fold increase 